\title{
An Environmentally Friendly Reflectometric Method for Bumetanide Determination in Pharmaceuticals
}

\author{
Fernanda Pollo, Rodrigo Sequinel, José Luiz Rufino, Patrícia Los Weinert, \\ Helena Redigolo Pezza, and Leonardo Pezza ${ }^{\dagger}$
}

São Paulo State University-UNESP, Institute of Chemistry of Araraquara, P. O. Box 355, 14801-970 Araraquara, SP, Brazil

\begin{abstract}
This paper describes a green analytical procedure for the determination of bumetanide using diffuse reflectance spectroscopy. The proposed method is based on reflectance measurements of a violet compound produced from a spot test reaction between bumetanide and $p$-dimethylaminocinnamaldehyde ( $p$-DAC) in an acid medium, using filter paper as a solid support. The best conditions for the reaction have been found by experimental design methodologies. All reflectance measurements were carried out at $525 \mathrm{~nm}$, and the linear range was from $1.37 \times 10^{-4}$ to $1.37 \times 10^{-3} \mathrm{~mol} \mathrm{~L}^{-1}$, with a correlation coefficient of 0.998 . The detection limit was estimated to be $3.98 \times 10^{-5} \mathrm{~mol} \mathrm{~L}^{-1}$. Five commercial medicines containing bumetanide were analyzed by the proposed method. No interferences were observed from the common excipients present in pharmaceutical formulations. The results were favorably compared with those obtained by the United States Pharmacopoeia procedure at 95\% confidence level.
\end{abstract}

(Received June 17, 2008; Accepted April 30, 2009; Published July 10, 2009)

\section{Introduction}

Diuretics have important therapeutic applications. They are used to treat high blood pressure and problems in fluid retention. Many athletes use the drugs to decrease weight in sports and to mask the use of other doping agents by altering their mechanism of excretion, mainly reducing their concentration in urine. ${ }^{1}$

Bumetanide, 3-(butylamino)-4-phenoxy-5-sulfamoylbenzoic acid (Fig. 1) is an important pharmaceutical compound, classified as a strong diuretic agent (loop diuretic). ${ }^{2}$ Bumetanide is used to treat edema associated with heart failure, renal and hepatic disorders and it has been used as an antihypertensive agent. $^{3}$

A few methods have been proposed for the determination of bumetanide in pharmaceuticals and biological fluids. High-performance liquid chromatography (HPLC) methods have been the main approach. ${ }^{4-6}$ Other techniques reported<smiles>CCCCCCCCCCOc1c(NS(N)(=O)=O)cc(C(=O)O)cc1OC</smiles>

Fig. 1 Structure of bumetanide.

† To whom correspondence should be addressed.

E-mail: pezza@iq.unesp.br are gas chromatography, ${ }^{7,8}$ capillary electrophoresis, ${ }^{9-11}$ spectrophotometry ${ }^{12}$ and flow-injection analysis with fluorometric detection. ${ }^{2}$ However, some of these methods are time-consuming or require expensive and sophisticated instruments. Furthermore, there is an evident demand to develop greener analytical procedures, because several current analytical methods employ a large amount of solvents and toxic reagents, which cause a potentially negative environmental impact. ${ }^{13}$ In this sense, a quantitative spot test by diffuse reflectance spectroscopy presents some advantages because the measurements are fast, easy to conduct and involve an extremely low consumption of reagents/solvents.

The development of reflectance spectroscopy was initially conceived for several applications, such as dye-stuffs, printing inks, paints and pigments, textiles paper, ceramics, building materials, metallurgy, and others. ${ }^{14}$ Nevertheless, the development of new techniques with optical fibers or reflectance spheres has changed this situation for the better. ${ }^{15}$ Too little attention has been given to diffuse reflectance spectroscopy as a quantitative technique, since it has not been possible to attain highly precise measurements from conventional spot tests. ${ }^{16}$ Few methods intended for a quantitative analysis spot test using diffuse reflectance spectroscopy have been reported in the literature. ${ }^{14,15,17-20}$

Combined spot test-diffuse reflectance spectroscopy offers advantages over other methods, such as simplicity and an extremely low consumption of reagents/solvents. Moreover, reflectance measurements can be performed in locus by using a very simple homemade reflectometer or a portable diffuse reflectance spectrophotometer, which are small, lightweight, inexpensive and battery operated, characteristics highly attractive for many applications in any location by nearly everyone..$^{21,22}$

To the best of our knowledge, there are no reports on the use of the combination spot test-diffuse reflectance spectroscopy for 
bumetanide determination in pharmaceuticals.

The aim of the present work has been to develop a simple, portable and environmentally friendly method for the rapid determination of bumetanide in pharmaceuticals. The proposed method is based on reflectance measurements in the visible region of the spectrum of a violet compound produced from the spot test reaction between bumetanide and $p$-dimethylaminocinnamaldehyde ( $p$-DAC) in an acid medium using filter paper as solid support.

\section{Experimental}

\section{Reagents and solutions}

All reagents and chemicals used were of analytical grade purity. The excipients used in the interference study were of pharmaceutical grade. The solvent used was methanol (HPLC grade, Mallinckrodt, Xalostoc, Mexico). $p$-DAC (Riedel-de Haën, Germany) was used to prepare a $3.44 \times 10^{-2} \mathrm{~mol} \mathrm{~L}^{-1}$ solution in methanol; the solution was stable for 1 week when stored in darkness at $4^{\circ} \mathrm{C}$. Hydrochloric acid (Mallinckrodt, Xalostoc, Mexico) at $2.13 \times 10^{-1} \mathrm{~mol} \mathrm{~L}^{-1}$ in methanol was prepared by adequate dilution of concentrated acid. Bumetanide standard was purchased from Deg, Brazil (purity 100.72\%). A $2.75 \times 10^{-3} \mathrm{~mol} \mathrm{~L}^{-1}$ stock standard solution of bumetanide in methanol was prepared by dissolving an appropriate amount of the drug in methanol. Working standard solutions were prepared by appropriate dilution of the stock solutions with methanol in order to construct an analytical curve from $1.37 \times 10^{-4}$ to $1.37 \times$ $10^{-3} \mathrm{~mol} \mathrm{~L}^{-1}$.

\section{Apparatus}

Reflectance measurements were made in a handheld integrating sphere (USP-REF, Ocean Optics, Dunedin, USA) connected to a fiber optic minispectrometer (USB4000, Ocean Optics). The USB4000 minispectrometer is equipped with a 2048 pixels Sony ILX511 CCD array detector. Software Spectra Suite (Ocean Optics) was used for the acquisition and storage of spectra. Eppendorf $(10-100 \mu \mathrm{L})$ and Brand $(100-1000 \mu \mathrm{L})$ micropipettes were used to measure smaller volumes in the experiment.

\section{Procedure}

For the spot test reaction the optimized conditions obtained in the experimental designs were used. The solutions were spotted onto $2.25 \mathrm{~cm}^{2}$ filter paper (Whatman 1). To carry out measurements, first $20 \mu \mathrm{L}$ of the reagent solution, then $20 \mu \mathrm{L}$ of the acid solution were spotted followed by addition of $20 \mu \mathrm{L}$ of the analyte solution. The solutions were spotted onto the center of the filter paper using a micropipette fixed in a holder according to a procedure by Tubino et al. ${ }^{17}$ A blank solution was prepared with $20 \mu \mathrm{L}$ of the reagent solution, $20 \mu \mathrm{L}$ of the acid solution and $20 \mu \mathrm{L}$ of methanol, and was spotted using the same procedure. Three reflectance measurements were performed for each aliquot and also for the blank, and the mean value was considered.

\section{Sample treatment}

The analyzed products were purchased from local manufacturers, and all were tested prior to the expiration date. Five pharmaceutical formulations (tablets and capsules) containing bumetanide and others components were analyzed. All of the commercial brands studied contained $1 \mathrm{mg}$ per tablet.

To develop this work, groups of 20 tablets or capsules of each

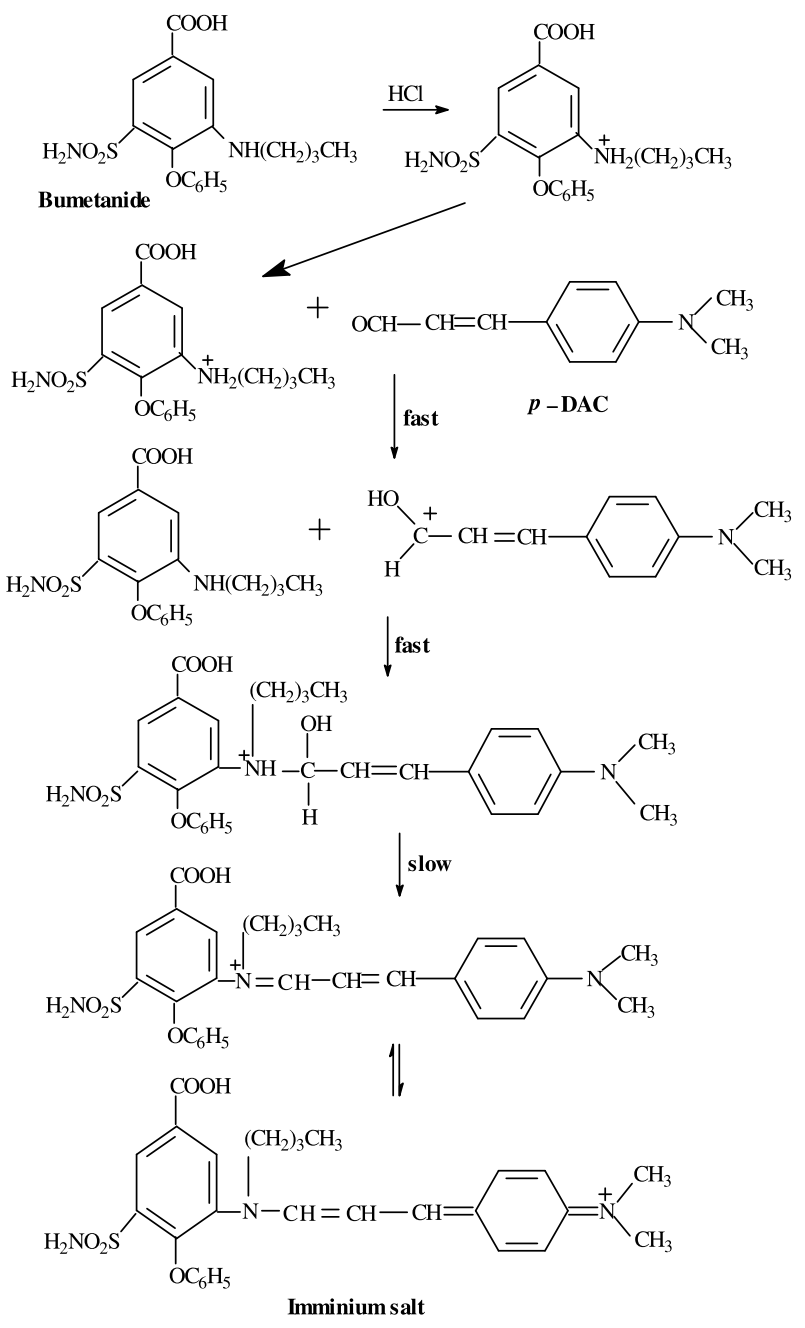

Scheme 1

one of the different used pharmaceutical preparations containing bumetanide were exactly weighed. The tablets after weighing were ground to a fine powder. A portion of this power equivalent to approximately $1 \mathrm{mg}$ of bumetanide was accurately weighed. The sample was shaken with methanol in a magnetic mixer for $5 \mathrm{~min}$ and diluted with methanol in a $10-\mathrm{mL}$ volumetric flask. After this, the solution was filtered in Whatman 41 filter paper and an aliquot of $20 \mu \mathrm{L}$ of this solution was taken in a spot test reflectance analysis.

In the case of the capsules, twenty capsules of one lot were exactly weighed (to obtain the average capsule content weigh); their contents were then carefully removed and finely powdered. The solutions were prepared in the same way as described concerning the aforementioned procedure.

\section{Results and Discussion}

The interaction between secondary aromatic amines and $p$-DAC in an acidic medium is assumed to take place through condensation of the secondary amino group with the protonated carbonyl group of the reagent to produce an imminium salt, that belongs to Schiff's base class (Scheme 1). ${ }^{23-25}$ In this study, from the reaction of bumetanide with $p$-DAC in an acid medium, a pink compound was formed on the surface of the filter paper, showing a reflectance spectrum with a maximum value of $A_{\mathrm{R}}$ 


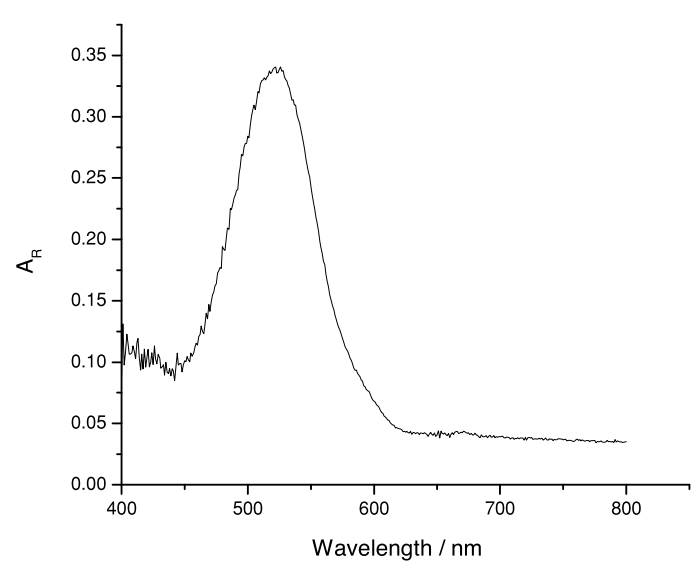

Fig. 2 Reflectance spectrum of the spot-test reaction on filter paper from bumetanide and $p$-DAC in a $\mathrm{HCl}$ medium. The maximum value of $A_{\mathrm{R}}$ was $525 \mathrm{~nm}$. Bumetanide concentration, $1.37 \times 10^{-3} \mathrm{~mol} \mathrm{~L}^{-1}$. Measurements were carried out at $25^{\circ} \mathrm{C}$.

(optical density for reflectance measurements) at $525 \mathrm{~nm}$ (Fig. 2). The stability of colored product was evaluated, and it was observed that the reflectance measurement remained stable for at least $24 \mathrm{~h}$ at room temperature $\left(25^{\circ} \mathrm{C}\right)$.

\section{Statistical analysis}

According to Wendlant and Hecht ${ }^{26}$ the color of the spot test should be uniform over the entire surface in order to ensure reproducible reflectance measurements. Presuming that the spot test reaction can be affected by multiple factors, the most favorable conditions for the reaction were investigated, including the addition order of the reagents. Previous assays performed in our laboratory showed that on the filter paper surface better spots were obtained under the following addition order: reagent, acid and the drug. ${ }^{19,20}$

In the sequence, the studies were directed according to the dependence of the reflectance signal as regards to the $p$-DAC and $\mathrm{HCl}$ concentrations. For this purpose, a central composite design was employed by means of the software Statistica 6.0. It was thus necessary to conduct twelve experiments in which the two variables were studied at five levels, including four central points for statistical validity within the range -1.41 to +1.41 ( $\alpha$ related to two factors and the two factor's levels), which corresponds to the $p$-DAC with a concentration range of $2.80 \times$ $10^{-2}$ to $4.47 \times 10^{-2} \mathrm{~mol} \mathrm{~L}^{-1}$ and $\mathrm{HCl}$ with a concentration range of $1.37 \times 10^{-1}$ to $3.41 \times 10^{-1} \mathrm{~mol} \mathrm{~L}^{-1}$. The center points are very important because they yield information concerning repeatability of the design. ${ }^{27}$ These ranges were chosen based on preliminary experiments.

Surface response plots constructed by plotting a reflectance signal as a function of the variables are shown in Fig. 3. As can be seen, the highest reflectance signal of the spot test was obtained when the concentrations of $p$-DAC and $\mathrm{HCl}$ were $3.44 \times 10^{-2}$ and $2.13 \times 10^{-1} \mathrm{~mol} \mathrm{~L}^{-1}$, respectively.

The quadratic regression model is give by:

$$
\begin{aligned}
Z=-1.07335+1.61664 x- & 10.65403 x^{2}+87.46511 y \\
& -1529.57995 y^{2}+84.49374 x y,
\end{aligned}
$$

where $Z$ represents the response factor corresponding to the absorbance value. The factors $x$ and $y$ are related to the $\mathrm{HCl}$ and $p$-DAC concentrations, respectively.

The responses of the model, the $R^{2}$ value, was greater than

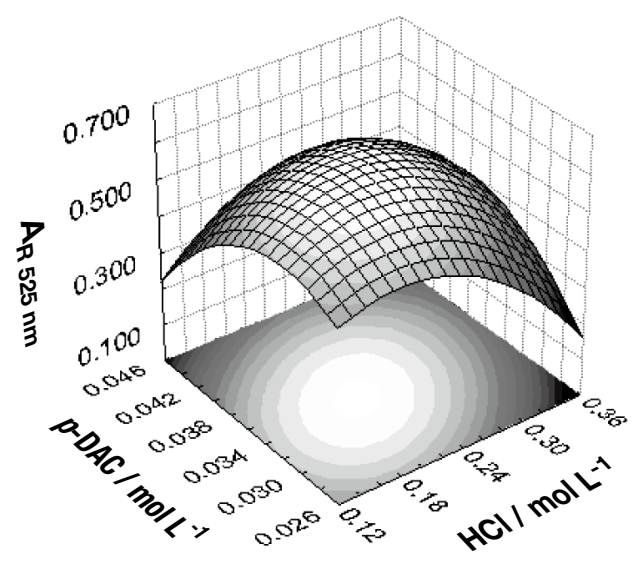

Fig. 3 Response surface from the central composite design for reflectance as a function of the $\mathrm{HCl}$ and $p$-DAC concentrations.

0.94. It confirms the assumption that the data fitted explain the relationship between the experimental results and the effects of the studied factors.

\section{Analytical data}

A developed analytical method was validated by evaluating the linear dynamic range, precision, limit of detection (LOD) and limit of quantification (LOQ) as well as by applying the standard addition technique.

A calibration curve was constructed from standard solutions of bumetanide with concentrations of $1.37 \times 10^{-4}$ to $1.37 \times 10^{-3}$ mol L ${ }^{-1}$. A linear relationship $(r=0.998)$ was obtained by plotting $A_{\mathrm{R}}$ vs. concentration of bumetanide $\left(\mathrm{mol} \mathrm{L}^{-1}\right)$, and the equation was $A_{\mathrm{R}}=0.05954+285.57 C$ (where $C=$ [bumetanide] $/ \mathrm{mol} \mathrm{L}^{-1}$ ). The limit of detection (LOD) and the limit of quantification (LOQ) were calculated according to Skoog et al.,$^{28}$ using the following expressions: LOD $=3 \sigma / b$ and $\mathrm{LOQ}=10 \sigma / \mathrm{b}$, where $\sigma$ is the standard deviation (SD) of twenty measurements of the blank, and $b$ is the slope of the analytical curves. The LOD and the LOQ were $3.98 \times 10^{-5}$ and $1.33 \times$ $10^{-4} \mathrm{~mol} \mathrm{~L}^{-1}$, respectively.

A precision assay was defined by determining the intraday and interday variations, expressed as relative standard deviation (RSD). The interday variation was evaluated over 3 days. The intraday precision and interday precision were studied for ten replicate assays of a $1.92 \times 10^{-4} \mathrm{~mol} \mathrm{~L}^{-1}$ bumetanide solution. The coefficients of variation were 0.42 and $1.43 \%$, respectively.

In order to investigate the presence of matrix effects on the proposed method, a recovery study was carried out. The recovery of bumetanide was examined by adding bumetanide reference solutions at three levels $\left(9.61 \times 10^{-5}, 1.92 \times 10^{-4}\right.$, and $2.88 \times 10^{-4} \mathrm{~mol} \mathrm{~L}^{-1}$ ) in three previously analyzed samples of different commercial brands. The recoveries obtained by the standard-addition method (Table 1) ranged from 99.8 to $100.1 \%$, evidencing the absence of any significant matrix effects on the proposed method.

\section{Study of interferences}

The interference of the common excipients, which often accompany bumetanide in pharmaceutical formulations commercialized in Brazil was determined by measuring the absorbance of a solution containing $8.23 \times 10^{-4} \mathrm{~mol} \mathrm{~L}^{-1}$ of bumetanide in the presence of $8.23 \times 10^{-4}$ and $8.23 \times 10^{-3} \mathrm{~mol} \mathrm{~L}^{-1}$ 
Table 1 Recovery study for bumetanide added in pharmaceutical formulations

\begin{tabular}{|c|c|c|c|}
\hline Sample & $\begin{array}{c}\text { Bumetanide } \\
\text { added/mol L-1 }\end{array}$ & $\begin{array}{l}\text { Bumetanide } \\
\text { found } / \mathrm{mol} \mathrm{L}^{-1}\end{array}$ & Recovery, \% \\
\hline \multirow[t]{5}{*}{ A } & - & $1.92 \times 10^{-4}$ & - \\
\hline & $9.61 \times 10^{-5}$ & $2.88 \times 10^{-5}$ & 99.9 \\
\hline & $1.92 \times 10^{-4}$ & $3.83 \times 10^{-4}$ & 99.5 \\
\hline & $2.88 \times 10^{-4}$ & $4.80 \times 10^{-4}$ & 100.0 \\
\hline & & & $\mu^{\mathrm{a}}=99.8 \pm 0.3$ \\
\hline \multirow[t]{5}{*}{$\mathrm{B}$} & - & $1.91 \times 10^{-4}$ & - \\
\hline & $9.61 \times 10^{-5}$ & $2.87 \times 10^{-4}$ & 99.9 \\
\hline & $1.92 \times 10^{-4}$ & $3.82 \times 10^{-4}$ & 99.5 \\
\hline & $2.88 \times 10^{-4}$ & $4.81 \times 10^{-4}$ & 100.7 \\
\hline & & & $\mu^{\mathrm{a}}=100.0 \pm 0.6$ \\
\hline \multirow[t]{5}{*}{$\mathrm{C}$} & - & $1.92 \times 10^{-4}$ & - \\
\hline & $9.61 \times 10^{-5}$ & $2.86 \times 10^{-4}$ & 98.0 \\
\hline & $1.92 \times 10^{-4}$ & $3.85 \times 10^{-4}$ & 100.5 \\
\hline & $2.88 \times 10^{-4}$ & $4.85 \times 10^{-4}$ & 101.7 \\
\hline & & & $\mu^{\mathrm{a}}=100.1 \pm 1.9$ \\
\hline
\end{tabular}

a. Average \pm standard deviation (SD) for the three determinations.

Table 2 Determination of bumetanide in commercial pharmaceuticals

\begin{tabular}{|c|c|c|c|c|}
\hline \multirow[b]{2}{*}{ Sample ${ }^{a}$} & \multicolumn{3}{|c|}{ Proposed method } & \multirow{2}{*}{$\frac{\text { Official method }^{29}}{\begin{array}{c}\text { Found }^{\mathrm{b}} / \mathrm{mg} \\
\text { tablet }^{-1}\end{array}}$} \\
\hline & Found $^{\mathrm{b}} / \mathrm{mg} \mathrm{tablet}^{-1}$ & $\begin{array}{c}t \text {-Value } \\
(2.78)^{\mathrm{c}}\end{array}$ & $\begin{array}{c}F \text {-Value } \\
(19.0)^{\mathrm{c}}\end{array}$ & \\
\hline A & $0.992 \pm 8.00 \times 10^{-3}$ & 2.12 & 1.77 & $1.00 \pm 6.00 \times 10^{-3}$ \\
\hline B & $0.989 \pm 4.00 \times 10^{-3}$ & 2.00 & 11.1 & $1.00 \pm 7.00 \times 10^{-3}$ \\
\hline $\mathrm{C}$ & $0.998 \pm 4.00 \times 10^{-3}$ & 0.76 & 1.90 & $1.00 \pm 6.00 \times 10^{-3}$ \\
\hline $\mathrm{D}$ & $0.988 \pm 9.00 \times 10^{-3}$ & 2.50 & 12.1 & $1.01 \pm 3.00 \times 10^{-3}$ \\
\hline $\mathrm{E}$ & $1.00 \pm 1.00 \times 10^{-2}$ & 0.50 & 1.98 & $1.00 \pm 7.00 \times 10^{-3}$ \\
\hline
\end{tabular}

a. Package labeled to contain $1 \mathrm{mg}$ bumetanide per tablet.

b. Average \pm standard deviation (SD), $n=3$.

c. Theoretical values of $t$ and $F$ at $95 \%$ confidence level.

interfering compounds under the same conditions described in the recommended procedure. The effect of each excipient was considered to be interference when the signal showed an error equal or greater than $3.0 \%$ in the determination of the drug. It has been found that lactose, polyvinypyrrolidone, magnesium stearate, talcum, silicon dioxide and starch do not interfere in the proposed method. The percentage of recoveries of bumetanide varied between 98.9 and $101.6 \%$, with RSD values of less than $3 \%$ for three replicates.

\section{Application of the proposed method}

The proposed method was applied for the determination of bumetanide in five commercially available pharmaceutical formulations. The results obtained by the reflectometric method were in good agreement ( $t$-test and $F$-test) with those obtained by the official HPLC method, ${ }^{29}$ and are summarized in Table 2. The calculated $t$ - and $F$-tests were less than the theoretical at 95\% confidence level, indicating that there was no significant difference between either methods concerning the precision and accuracy in the determination of bumetanide in pharmaceuticals.

\section{Conclusion}

This study showed the feasibility of diffuse reflectance spectroscopy to determine bumetanide in pharmaceutical formulations by using a spot test on a filter paper surface. A multivariate analysis provided a definition of the minimum concentration of the reagents for the maximum reflectance signal. Comparing with other reported methods for bumetanide determination in pharmaceuticals, diffuse reflectance spectroscopy using spot test offers advantages such as simplicity, portability, rapidness and extremely low consumption of reagents/solvent (environmentally friendly method).

Green analytical chemistry is in its initial stage of development, but there is a clear trend towards fast and consistent growth. Soon, analytical methods showing high performance, but which are not environmentally friendly, tend to be unacceptable for stimulating the development of cleaner methods. This will contribute to the development of an essencial environmental conscience for the future. This paper is a contribution towards a green chemistry.

\section{Acknowledgements}

We would like to thank FAPESP, CNPq Foundations (Brazil) for financial support and Sandra Ferreira Lucas Soares for technical and scientific support.

\section{References}

1. L. Amendola, C. Colamonici, M. Mazzarino, and F. Botrè, Anal. Chim. Acta, 2003, 475, 125.

2. P. Solich, C. K. Polydorou, M. A. Koupparis, and C. E. Efstathiou, Anal. Chim. Acta, 2001, 438, 131.

3. J. E. F. Reynolds, "Martindale the Extra Pharmacopoeia", 31st ed., 1996, Royal Pharmaceutical Society, London, 836.

4. M. J. Legorburu, R. M. Alonso, R. M. Jimenez, and E. Ortiz, J. Chromatogr. Sci., 2001, 39, 425.

5. S. Carda-Broch, J. S. Esteve-Romero, and M. C. García-Alvarez-Coque, Anal. Chim. Acta, 1998, 375, 143.

6. P. Campins-Falco, R. Herraez-Hernandez, and A. Sevillano-Cabeza, J. Chromatogr., B, 1993, 612, 245.

7. D. Carreras, C. Imaz, R. Navajas, M. A. Garcia, C. Rodriguez, A. F. Rodriguez, and R. Cortes, J. Chromatogr., A, 1994, 683, 195.

8. H. W. Hagedorn and R. Schulz, J. Anal. Toxicol., 1992, 16, 194.

9. H. Siren, K. Luomanpera, T. Tyopponen, S. Rovio, P. Vastamaki, and P. Savolahti, J. Biochem. Biophys. Methods, 2004, 60, 295.

10. E. Gonzalez, A. Becerra, and J. J. Laserna, J. Chromatogr., $B, \mathbf{1 9 9 6}, 687,145$.

11. E. Gonzalez and J. J. Laserna, Electrophoresis, 1994, 15, 240.

12. L. Zivanovic, S. Agatonovic-Kustrin, M. Vasiljevic, and D. Radulovic, Acta Poloniae Pharmaceutica, 1992, 49, 9.

13. W. R. Melchert and F. R. P. Rocha, Talanta, 2005, 65, 461.

14. A. Ghauch, C. Turnar, C. Fachinger, J. Rima, A. Charef, J. Suptil, and M. Martin-Boyer, Chemosphere, 2000, 40, 1327.

15. A. Ghauch, C. Turnar, C. Fachinger, J. Rima, A. Charef, 
J. Suptil, and M. Martin-Boyer, Talanta, 1999, 48, 385.

16. D. Kealey, Talanta, 1972, 19, 1563.

17. M. Tubino, A. V. Rossi, and A. M. E. Magalhães, Anal. Lett., 1997, 30, 271.

18. F. A. A. Matias, M. M. D. C. Vila, and M. Tubino, Sens. Actuators, B, 2003, 88, 60 .

19. M. A. Gotardo, J. O. Tognolli, H. R. Pezza, and L. Pezza, Spectrochim. Acta, Part A, 2008, 69, 1103.

20. L. S. Lima, P. Weinert, S. Lemos, R. Sequinel, H. R. Pezza, and L. Pezza, Spectrochim. Acta, Part A, 2009, 71, 1999.

21. M. P. Arena, M. D. Porter, and J. S. Fritz, Anal. Chem., 2002, 74, 185.

22. N. C. Dias, M. D. Porter, and J. S. Fritz, Anal. Chim. Acta, 2006, 558, 230.

23. N. H. Zawilla, M. A. A. Mohammad, N. M. El Kousy, and S. M. El-Moghazy Aly, J. Pharm. Biomed. Anal., 2002, 27,
243.

24. Z. A. El Sherif, M. I. Walash, M. F. El Tarras, and A. O. Osman, Anal. Lett., 1997, 30, 1881.

25. M. Qureshi, S. Z. Qureshi, and A. Mohammad, J. Phys. Chem. A, 1975, 79, 116.

26. W. W. Wendlant and H. G. Hecht, "Reflectance Spectroscopy", 1996, Interscience Publishiers, New York, 297.

27. E. C. Gil, A. Van Schepdael, E. Roets, and J. Hoogmartens, J. Chromatogr., A, 2000, 895, 43.

28. D. A. Skoog, F. J. Holler, and T. A. Nieman, "Principles of Instrumental Analysis", 5th ed., 1998, Harcourt Brace Company, Philadelphia, 11.

29. United States Pharmacopeia, 26th ed., 2003, United States Pharmacopeial Convention, Rockville, 275. 